\title{
Methodology of electric motor testing on the hybrid engine test bench
}

This paper presents a basic methodology and equipment setup used for an electric motor designed for light-duty vehicles, testing on a hybrid engine test bench equipped with an active AC dynamometer. The methodology used during the test was based on the appropriate regulation (UN-ECE Regulation 85). An example of mechanical performance measurements is presented, as well as an overall layout of the measurement devices used for testing, including a scheme detailing all electrical connections between the equipment employed during the test. The paper takes into consideration the necessity of development and subsequent improvements of the methodology employed during testing of e-motors, which due to the highly changeable and competitive automotive environment, will undoubtedly have a gradually increasing share and significance in the automotive industry.

Key words: e-motor, electric motor, hybrid engine test bench, testing methodology and equipment, active AC dyno, UN-ECE Regulation 85

\section{Introduction}

The high prices of fossil fuels on the global markets, growing demand for green and low-carbon energy, as well as fierce competition and more and more stringent emission legislation have exerted great pressure on automakers and manufacturers, forcing them to search for and implement new, more efficient powertrain solutions focused on reduced fuel consumption and emission levels [4, 6].

The most reasonable solution seems to be small displacement engines, however, as it is now known, they are not the most optimal ones. Simultaneously, further optimization of existing internal combustion engine solutions generates great costs and seems to be quite limited from the technical point of view [5]. Now it is seen that automakers are more and more interested in implementing electric engines in the way of hybrid applications or pure electric drivetrains equipped with very sophisticated control units $[3,9]$. According to the ERTRAC study, powertrain electrification is the main leverage to reduce global $\mathrm{CO}_{2}$ emissions from transport sources [12] and only a high level of electrified vehicles in fleet mix show a chance to meet the decarbonization challenge in European Union presented in the EU Transport White paper to reduce the overall $\mathrm{CO}_{2}$ tank-to-wheel emissions by 60\%, based on 1990 emission level [7].

At the end of the $19^{\text {th }}$ century and at the beginning of the $20^{\text {th }}$ century, electric cars constituted a significant part of the fleet. Despite many advantages, electric motors have lost the battle with the internal combustion engine. The biggest disadvantages were low range and limited battery capacity as well as the substantial weight of the battery itself $[9,14]$. The internal combustion engines of the day offered greater power and mileage. Additionally, the introduction of the electric starter to the market made the starting procedure of combustion engines much easier than previously (when manual cranking had been quite normal) [14].

At present, the development and introduction of innovative electronic solutions have made electric motors better, quieter and much more powerful. Currently, in the era of increasing requirements of emission standards, electric engines are once again the center of attention, making up a crucial development point for the entire automotive industry $[3,5,9]$.

The market share of hybrid-electric vehicles was rising slowly in the last years to $1.8 \%$ of all new cars sold in the European Union in 2016. Plug-in-hybrid and electric vehicles were at about 1\% among all vehicles sold in 2016 [11]. Current European electric-vehicles sales are of about 1.5\% of all new vehicle registration and can rise to about $5 \%$ in 2021 and to bigger percentage in next years to 2025, when a significant uptake of the electric vehicle market is to be expected [3].

At present four type of electrified drivetrains that use electric motors are considered in modern vehicles: HEVs (Hybrid electric vehicles), PHEVs (Plug-in hybrid electric vehicles), BEVs (Pure battery electric vehicles), and HFCEVs (Hydrogen fuel cell electric vehicles) [1, 9]. Electric (battery) powertrain consists of onboard high-energy battery or supercapacitor, or both of them, electric energy converters (Inverter), electric motor and drivetrain system $[1,14]$. Energy and power demand must be sufficient to deal with:

- The air drag that is proportional to vehicle frontal area, air drag coefficient and the square of the speed.

- Rolling resistance that is proportional to vehicle mass and rolling resistance coefficient.

- Gravity at ascends.

- Other power losses (internal and external) e.g. due to wear.

- Provide power to on-board equipment and sub-systems e.g.: lights, air conditioning (A/C) system, radio, power drives, electronic control units, etc. [14, 17].

Currently, the $2^{\text {nd }}$ generation of PEV technology is under development, with improved batteries, more driving mileage, followers adequate infrastructure. The $3^{\text {rd }}$ generation of PEV is planned for 2020-2025 time frame, with improved batteries and vehicles to make core market for PEVs competitive [6]. The main challenges of vehicle electrification are currently following [1]: 
- Solution to environmental performance,

- Cruising range, battery charging time,

- Infrastructure,

- Cost/affordability.

Apart from the on-going improvements of electric vehicles technology making EVs competitive with the conventional ICE vehicles on multiple markets some legislators and R\&D organizations are constantly working on test methods and test equipment assigned for this type of vehicles and powertrains.

The concept of testing and quantifying the performance of the electric motors in the industry is not new, but due to the growing popularity of this type of the engines in the automotive industry (hybrid and electric solutions), it is undoubtedly necessary to get familiar with the requirements and research methodology. Test method related to pure electric vehicles, hybrid electric and compressed hydrogen fuel cell hybrid vehicles were part of the works on new WLTP (Worldwide harmonized Light vehicles Test Procedures) carried out by Informal Working Group (IWG) on WLTP of United Nation Economic Commission for Europe (UN ECE), Inland Transport Committee, World Forum for Harmonization of Vehicle Regulation (GRPE). Results of those works were introduced to the Global Technical Regulation (GTR) no. 15 of UN ECE in Annex 8. Currently, Proposal for Amendment 4 to GTR 15 for WLTP test procedure is under discussion [13]. Another IWG - Electric Vehicles and Environment (EVE IWG) of this UN ECE World Forum is working on the development of new UNECE GTR determining test methods for the main issues related to $\mathrm{EV}$ vehicles as [16]:

- Power determination of the electrified vehicles.

- Electrified vehicle durability issue (continuing research on EV battery performance and durability).

- Methods of quantifying the energy consumption.

\section{Electric motor testing methodology on test bench for a hybrid powertrains}

\subsection{Methods of electric moto testing UN ECE Regulation No. 85}

The existing test methodology is widely described in the UN-ECE Regulation 85 [15]. This regulation requires to obtain and map the power curve as a function of the engine or electric motor speed in terms of the power at full load indicated by the manufacturer for internal combustion engines or electric drivetrains. The regulation determines also the measurement of the maximum 30 minutes power of electric drivetrains intended for the propulsion of motor vehicles of categories $\mathrm{M}$ and N1 [15].

Within its structure, UN-ECE Regulation 85 defines the main definitions and related technical concepts. In the case of electric motors, electric drivetrains are composed of controllers and a motor and can be used for propulsion of vehicles (as the sole means of propulsion). The "net power" is defined as the power obtained on a test bench at the end of the crankshaft or its equivalent at the corresponding engine or motor speed, with the auxiliaries [15].

UN-ECE Regulation 85 also specifies the auxiliaries used during the tests determining its position and locations on the test bench and also specifying some overall technical conditions. The regulation specifies especially the cooling conditions that need to be maintained during the test. According to the regulation, the electric drivetrain shall be equipped with auxiliaries (radiator, fan, fan cowl, pump, thermostat in case of liquid - cooling or air filter, cowl, blower, temperature adjustment system in case of air cooling). The radiator, the fan, the fan cowl, the water pump and the thermostat shall be located on the test bench in the same relative position as when mounted on the vehicle. The cooling-liquid circulation shall be activated by the drivetrain water pump only. Cooling of the liquid may be produced either by the drivetrain radiator, or by an external circuit, provided that the pressure loss of this circuit and the pressure at the pump inlet remain substantially the same as those of the drivetrain cooling system. Where the fan, radiator and fan cowl cannot conveniently be fitted into the test cell, the power absorbed by the fan when separately mounted in its correct position in relation to the radiator and cowl (if used), shall be determined at the speed corresponding to the motor speeds used for measurement of the motor power, either by calculation from standard characteristics or by means of practical tests. This power, corrected to standard atmospheric conditions should be deducted from the correct power. It is notable that the electric drivetrain shall be supplied from a DC voltage source with a maximum voltage drop of 5\% depending on time and current (periods of less than 10 seconds excluded) [15].

UN-ECE Regulation 85 also determines the approval of the propulsion system within its net power measured in accordance with the specified procedure. As mentioned previously, the net power is the power obtained on the test bench on the crankshaft at the specified engine speed together with auxiliary equipment. It is notable that net power is determined under atmospheric reference conditions. The maximum 30-minute power is the maximum net power of the electric motor which the drive system can produce (on average) over a period of 30 minutes [15].

According to UN-ECE Regulation 85, the determination of net power proceeds as follows: the engine and its set of devices must be conditioned at $25( \pm 5)^{\circ} \mathrm{C}$ for at least two hours. The net power test is performed at the maximum setting of the power regulator. Before starting the test, the engine operates on the test bench for three minutes, generating a power equal to $80 \%$ of the maximum power at the speed specified by the manufacturer. The measurements are made at different engine speeds to accurately determine the power curve between zero and the maximum speed recommended by the manufacturer [15].

The determination of the maximum 30-minute power in accordance with the regulation is conducted as follows: the engine and its set of devices must be conditioned at 25 $( \pm 5)^{\circ} \mathrm{C}$ for at least four hours. The electric motor works on the test bench with the power recommended by the manufacturer to obtain the maximum 30-minute power. The engine speed must be within the range for which the net power exceeds $90 \%$ of the maximum power measured in accordance with the regulations. The engine speed in the point of the determination of the 30-minute power should be recommended by the manufacturer. Engine speed and power must be recorded and post-processed accordingly to 
the requirements in the regulation. The power must be within $\pm 5 \%$ of the power at the start of the test. The maximum 30 -minute power is the average power obtained within thirty minutes of the start of the test [15].

UN-ECE Regulation 85 specifies the data evaluation methodology. In encapsulated form, the net power and the maximum 30 minute power of the electric motor specified by the manufacturer are accepted if for maximum power the results differ by no more than $\pm 2 \%$ and for other measuring points on the power curve by no more than $\pm 4 \%$ from the values measured by the technical service on the unit under test submitted for testing. It is notable that the e-motor speed tolerance is $\pm 2 \%$.

It is worth mentioning that all the such performed at BOSMAL incorporating the measurements of the net power and the 30-minute net power was conducted in accordance with the latest version of UN ECE Regulation No. 85 (i.e. revision 1, supplement 6, paragraphs 5.3.1 and 5.3.2) [15]. The work directly referred to net power and torque measurements, determination of 30-minute net e-motor power and the proper and adequate interpretation of the results obtained.

\subsection{Test bench for internal combustion engines (ICEs) and hybrid powertrains as the indispensable equipment for e-motors testing}

Nowadays special dedicated engine test stands using alternating current (AC) dynamometers are widely used during the testing of internal combustion engines (ICE) and hybrid powertrains. In general, this type of the engine test bench with an active AC dynamometer can also be used during testing of entire vehicle drivetrains.

The engine test stand with an active AC dyno installed at BOSMAL, together with all equipment designed for research, development and type approval is dedicated to performing research activities in the range of testing and operational simulations of light (LD), medium (MD) and heavy-duty (HD) engines fueled with a gasoline, diesel fuel, LPG, CNG, synthetic fuels and biofuels, as well as hybrid and fully electric solutions. The drivetrains which it is possible to test can be a classic engine unit consisting of an internal combustion engine (ICE) only, but also hybrid drivetrains and finally entirely electric motors equipped with the associated control hardware. The engines tested on such a test bench are able to be operated and tested under steady state, transient and dynamic (fast-changing) conditions. This approach incorporating a specific list of a highly advanced equipment is fully consistent with current automotive trends appearing on the market which are noticeably focused on hybrid and electric motors applications [8].

It is noteworthy that BOSMAL laboratory has currently on its disposal one the abovementioned test stands equipped with an active engine dynamometer with an asynchronous AC motor and a power unit assigned for electric motors (shown in Fig. 1 and Fig. 2). This equipment configuration gives wide possibilities to test both internal combustion engines and hybrids consisting of both the internal combustion engine and electric motors, but also enables testing of electric motors themselves. In the case of testing hybrid or electric motors, a common, superior automation surveillance system gives the ability to perform dynamic tests and perform all the measurements requested by the related regulations (e.g. UN-ECE Regulation 85) [8].

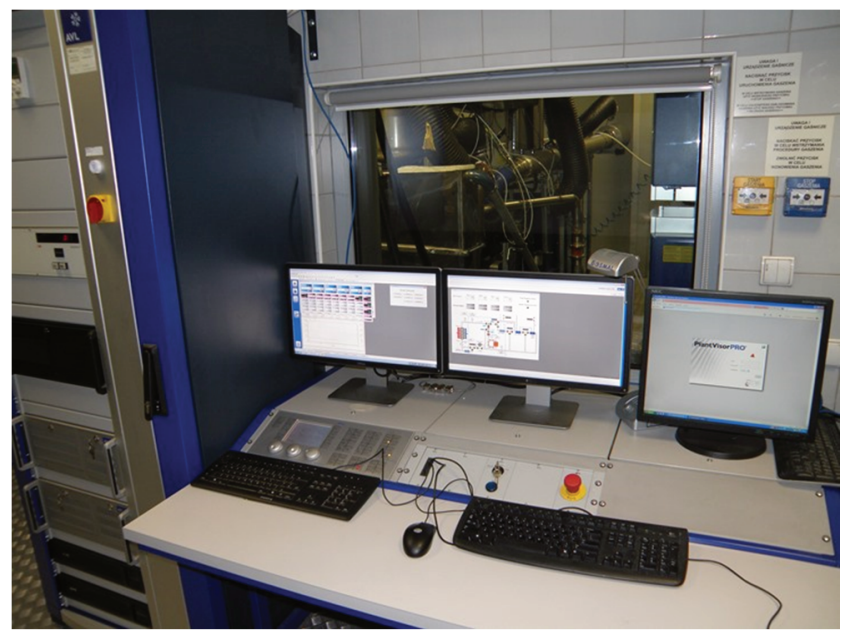

Fig. 1. The equipment used during testing: PUMA Open software (updated to version 1.5.5)

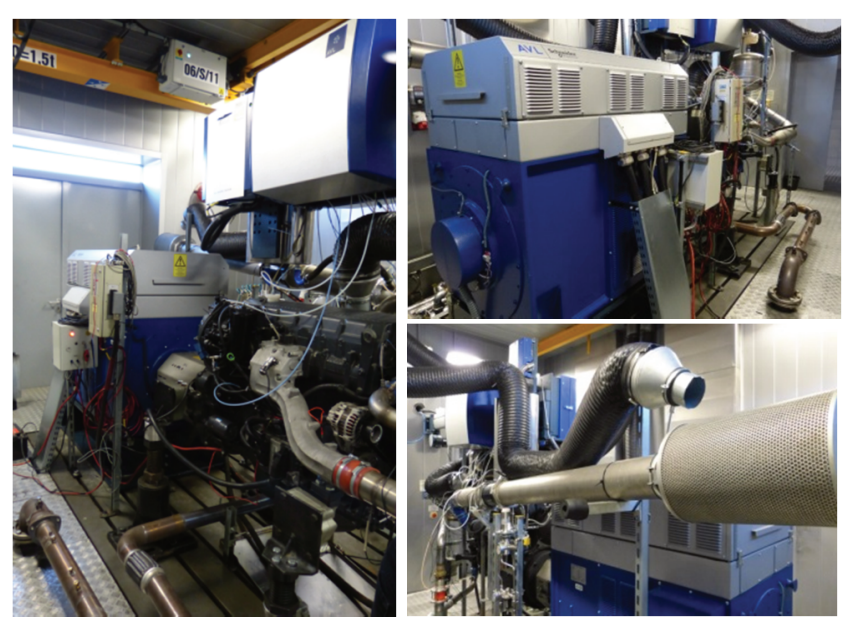

Fig. 2. The equipment used during testing: active AC dyno and auxiliaries

It is evident that dynamic tests are currently indispensable in development studies and for type approval, as well as in durability research. A dedicated test stand for testing of hybrid and electric drivetrains facilitates execution of tests in accordance with the applicable regulations and standards, but also gives the ability to prepare any programmable tests according to any requirements - which is extremely important from the research and development point of view. An example of such a practical application is a simulation of the behavior of the hybrid drivetrain system in real working conditions while operating in a vehicle.

\subsection{The problematic issues occurring during e-motors testing}

Electric drivetrains in automotive applications contain an e-machine, power electronics, an energy storage device, charging electronics, transmission and some peripheral equipment. The challenges for e-machines in vehicular applications are extensive and they have to meet many requirements, for example: high efficiency, low cost and weight, dynamics, packaging, high power, climatic robustness, acoustic behavior and EMC, thermal robustness 
and mechanical stability [10]. In the past many directcurrent motors were used in electric vehicles. Today the most usable technology are permanent magnet synchronous machines (PSM) and asynchronous machines (ASM), or sometimes also electrically excited synchronous machine (ESM) [10].

The research and development field reports that testing the e-motors is strictly connected with the certain problems related with the signal measuring nature, efficient data postprocessing and transparent final data evaluation methodology. Some major problems are briefly mentioned below and detailed in the literature $[2,10]$ :

- Fast switching inverters and the power analysis reliability in terms of sufficient sampling rates;

- A dynamic, fast-changing and transient nature of e-motor testing in all operational conditions;

- The necessity of permanent monitoring of the current harmonics;

- The issues related with a raw data storage, data postprocessing and high data accessibility methods.

The abovementioned problems during e-motor performance measurements are strictly related to the hardware and software used and also with their technical potential. In this context, the power analyzer units used must be dedicated and optimized for automotive application purposes indicating satisfactory technical parameters. For that reason, a great amount of costs must be necessarily borne by automotive research and development institutes just in order to be equipped with the highest quality equipment ensuring a highly reliable data recording and enabling transparent final data evaluation.

\subsection{Testing equipment and capabilities used during the test}

The test stand employed during the e-motor tests incorporated an active alternating current (AC) dynamometer with maximum power of $220 \mathrm{~kW}$, a power battery unit, AVL e-storage with a nominal power of $160 \mathrm{~kW}$ to supply the e-motor, and power analyzer (Yokogawa WT 1800) for voltage and current measurement. The AVL e-storage DC power unit featured an output voltage range of 8-800 $\mathrm{V}$ and a maximum current output of $600 \mathrm{~A}$. The test stand was controlled by the AVL PUMA Open automation platform. Additionally, the motor required connection to an external liquid cooling system with the PID temperature and flow control and not to exceed $60^{\circ} \mathrm{C}$ (measured at the motor outlet). Dielectric transformer oil was used as a coolant due to the direct winding cooling solution employed.

The mechanical performance of an electric motor in terms of net torque $T=f(n)$ and power $P=f(n)$, was measured at the motor crankshaft over the entire speed range. The e-motor as installed on the test bench is depicted in Fig. 3. The inlet and outlet of the oil cooling system as well as the main electrical connections are depicted in Fig. 4.

The equipment used during testing: PUMA Open software, AVL e-storage (power battery unit), power analyzer (Yokogawa unit) and electric inverter (coolant pump speed control) are shown in the following figures: Fig. 5, Fig. 6, Fig. 7 (respectively).



Fig. 3. The e-motor installed on the engine test bench equipped with an active AC dyno

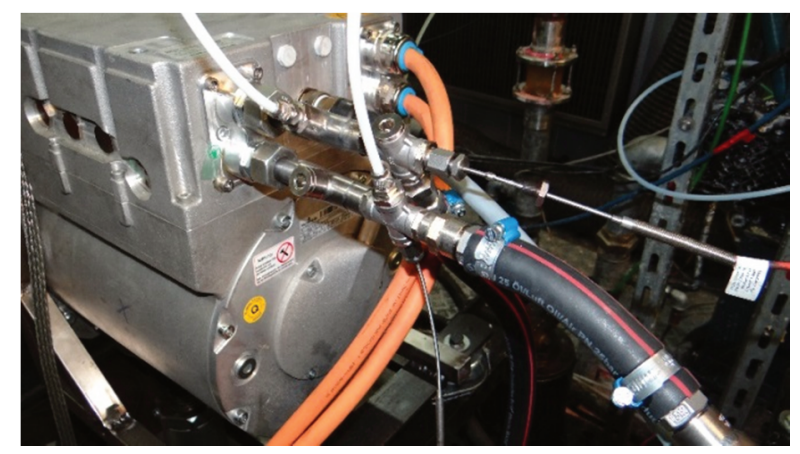

Fig. 4. The motor oil cooling system in/outlet and the electrical connections
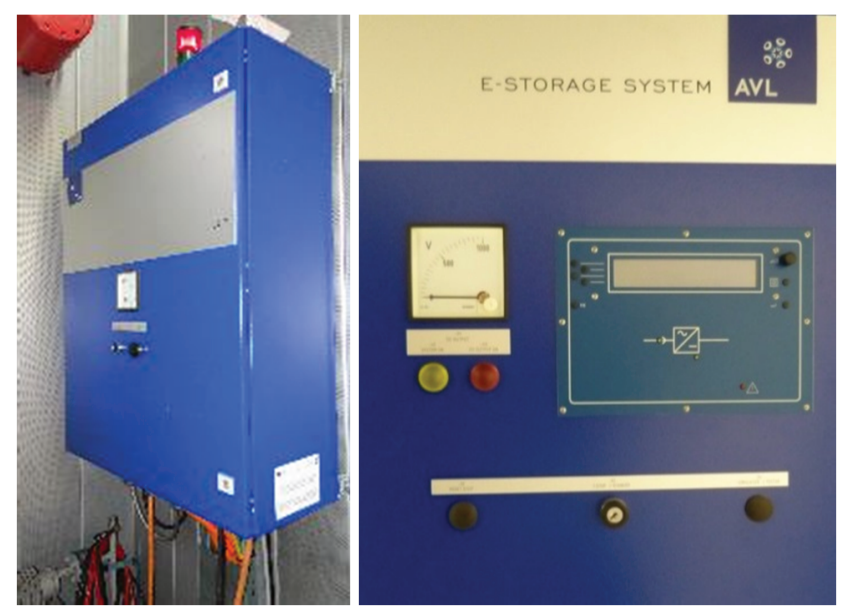

Fig. 5. The equipment used during testing: AVL e-storage (power battery unit)
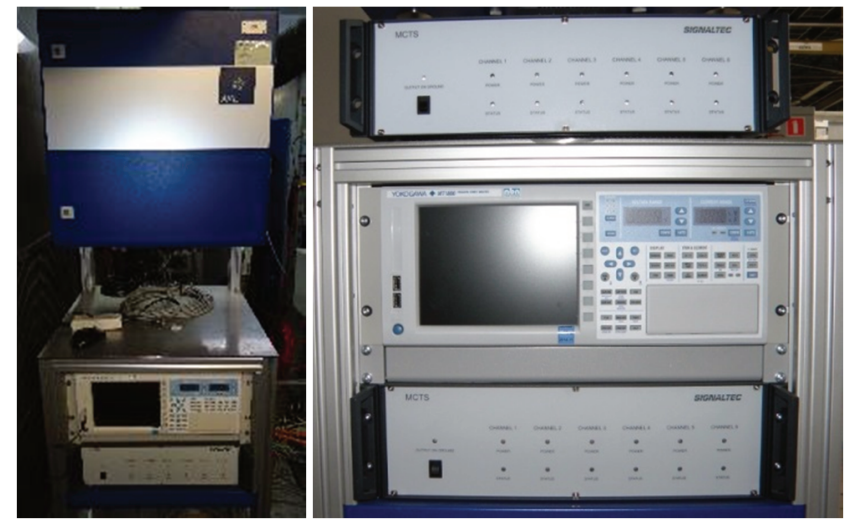

Fig. 6. The equipment used during testing: power analyzer (Yokogawa unit) 


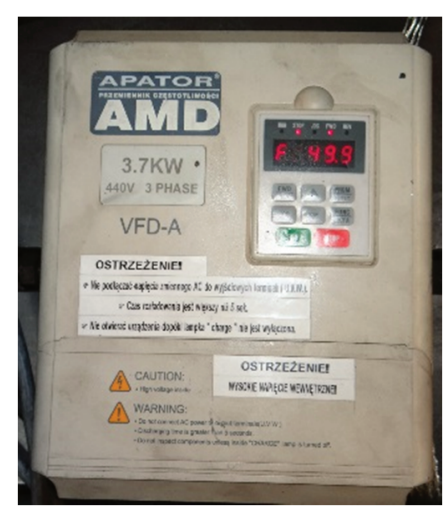

Fig. 7. The equipment used during testing: the electric inverter (coolant pump speed control)

BOSMAL's overall capabilities and functionalities in terms of testing e-motors are enumerated below. As mentioned above, at this point, BOSMAL has at its disposal a hybrid test cell (no. 19) which is equipped with an up-todate e-storage unit and a portable low voltage battery emulator. The test bench software incorporates the following functionalities and has the following characteristics [8]:

- AVL PUMA OPEN 1.5.3

- AVL iGEM

- AVL ISAC

- AVL InMotion

AVL e-storage DC Power Unit is characterized by the following parameters:

- Nominal capacity: $160 \mathrm{~kW}$

- Output voltage: 8-800 VDC

- Output current (max): $600 \mathrm{~A}$

- Permanently fixed on test bench no. 19

A regatron low voltage battery emulator is characterized by the following parameters:

- Nominal capacity (max): $20 \mathrm{~kW}$

- Output voltage: $65 \mathrm{~V}$

- Output current (max): 385 A

- Portable unit (mobile usage)

\subsection{Testing methodology and description of the unit under test}

The main aim of the test activities was to measure and validate the mechanical performance of an electric motor in terms of net torque $T=f(n)$ and power $P=f(n)$ measured at the motor crankshaft over the entire speed range. The secondary activities were to determine the nominal power value generated at rated speed and verify its stability over time. This is referred to as the 30-minute net power test with $1 \mathrm{~Hz}$ data acquisition, which was conceptualized as a verification of measured/declared nominal power values over 30 minutes (criterion: within $\pm 5 \%$ tolerances) [15]. The measurement of mechanical performance was conducted in the speed range of 0-6000 rpm with a step of $\Delta \mathrm{n}=$ $250 \mathrm{rpm}$. The measurement of net torque and power values were taken as an average of 30-second steps [15]. In parallel to the mechanical power on the motor's shaft, the electric active power was also measured using a Yokogawa power analyzer.

As mentioned above, the measurements of the net power and the 30-minute test were conducted in accordance with UN ECE Regulation No. 85, revision 1, supplement 6, paragraphs 5.3.1 and 5.3.2 [15].

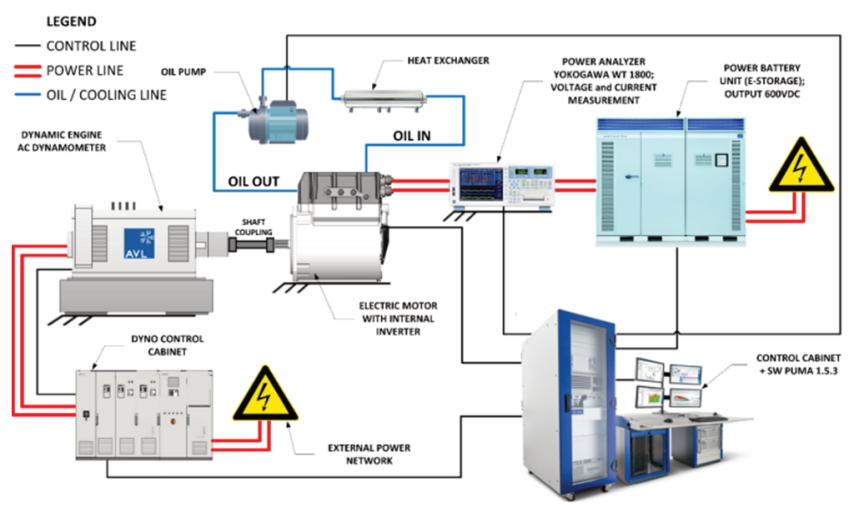

Fig. 8. The overall concept of the electrical connections and the equipment employed during the testing

The unit under test was a PMSM (permanent magnet synchronous three-phase alternating current (AC) motor), mono unit (one motor integrated with the onboard inverter electronics), with 6 poles. Nominal supply voltage was 600 volts direct current (VDC) and an additional 9-32 VDC power supply was used for the control electronics. The basic characteristics of the electric motor were the following: operating speed range 0-6000 rpm, nominal net power $80 \mathrm{~kW}$ at $6000 \mathrm{rpm}$ and maximum overload power $88 \mathrm{~kW}$ available for maximum 15 seconds. In essence, the electric motor was supplied with 600 volts direct current (VDC) from the AVL e-storage DC power unit. It is notable that the electric motor was internally integrated with the control unit incorporating the following functionalities: controlling the inverter which converts direct current into alternating current and is responsible for starting and driving the motor, protection functions (motor temperatures, overload, overcurrent and overvoltage), communication/diagnostic interfaces and digital I/O (inputs / outputs) to interface with external control systems. The electric motor was interfaced with the test bench control system using CAN bus and digital I/O. The overall concept of the electrical connections and the layout of the equipment employed during the tests are depicted in Fig. 8.

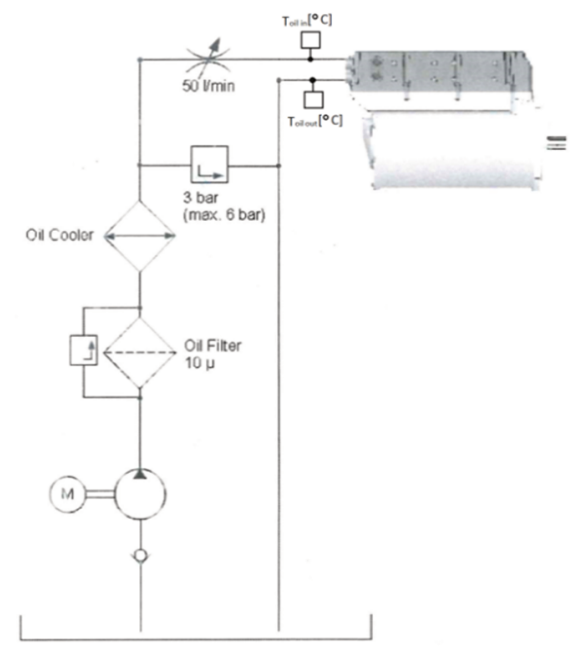

Fig. 9. The external circuit of the cooling system applied in the tested e-motor 
As mentioned above the e-motor was connected to the external liquid cooling system in which the coolant temperature and flow were monitored and operated by the PID controller. The scheme showing the external circuit controlling the proper oil recirculation and at the same time the cooling functionality has been depicted in Fig. 9.

\subsection{Example of test results}

The basic characteristic of the electric motor is presented on Fig. 10. The measurement of mechanical performance was conducted over an entire operating speed range of $0-6000 \mathrm{rpm}$ with a step of $\Delta \mathrm{n}=250 \mathrm{rpm}$. The measurements of net torque and power values were taken as an average of 30 seconds steps. The motor characteristic can be distinguished into a part of constant torque $(250 \mathrm{Nm})$ in a range of 0-3000 rpm and the part of constant power (80 $\mathrm{kW}$ ) between 3000-6000 rpm.

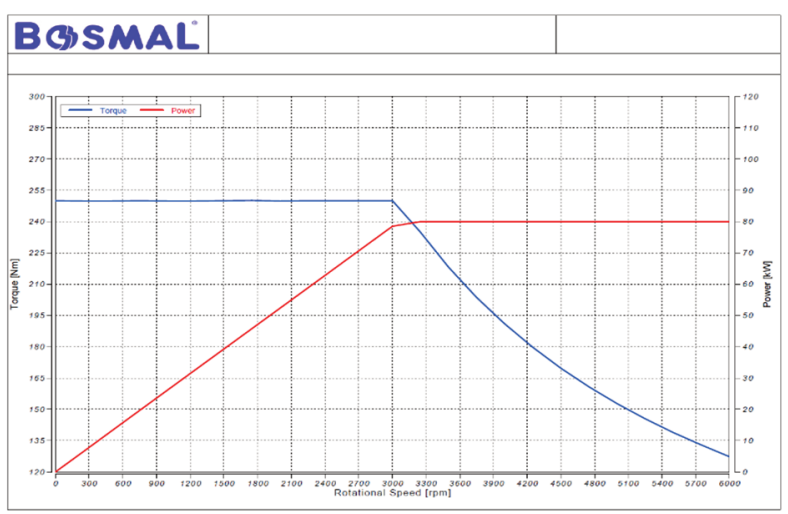

Fig. 10. E-motor rated power and torque characteristic as a function of speed, $T=f(n), P=f(n)$

The next test activities were a determination of the nominal power value generated at rated speed and verifying its stability over the set period of time. This is referred to as 30-minute net power test with $1 \mathrm{~Hz}$ data acquisition, which was comprehended as a verification of measured to declared nominal power value over 30 minutes and within $\pm 5 \%$ tolerances [15]. The results are presented in Fig. 11 .

\section{Conclusions and summary}

The tests conducted as well as the methodology and related equipment employed have led to the following overall conclusions, as described below:

a) due to the constantly rising share of electric motors in the automotive industry, demand for the type of tests presented above will grow significantly;

b) test benches for testing combustion engines can be adapted for electric motor tests, following implementation of an additional set of measuring equipment and specified power supply units;



Fig. 11. E-motor nominal power verification as a function of time (30 minutes $), P \max =f(t=1800 \mathrm{~s})$

c) testing e-motors' performance involves many problematic issues related to the signal measuring aspect, efficient data post-processing and transparent final data evaluation methodology;

d) the tests conducted the incorporated determination of net power and torque measurements, as well as the socalled 30-minute net power test in accordance with UNECE Regulation 85;

e) the electrical and mechanical performance results presented allowed determination of the overall electric motor efficiency over the entire speed operating range, the results of what will be presented in future publications;

f) the electrical power used for supplying the motor can be recovered - to a great extent - by using an active AC dynamometer;

g) the overall energy balance for an electric motor is much more advantageous than in case of combustion engines - a point which will be further investigated and discussed in the future.

It is noteworthy that some of the abovementioned conclusions will be undoubtedly expanded and put under detailed investigation during future tests.

Summarizing, electric motor testing for automotive applications is a new and quite complex issue. It is noteworthy that developing a dependable and credible test methodology for electric motor testing reveals great significance from the research and development point of view, especially taking into consideration the fact that electric motors will make up a substantial and still increasing share of drivetrains used in the automotive industry in the future.

\section{Acknowledgement}

The work described in this paper was carried out within the framework of the INNOMOTO Sectoral Programme, project no. POIR. 01.02.00-00-0308/16.

\section{Nomenclature}

$\begin{array}{ll}\text { AC } & \text { Alternating Current } \\ \text { A/C } & \text { Air Conditioning } \\ \text { ASM } & \text { Asynchronous Machine } \\ \text { BEV } & \text { Battery Electric Vehicle } \\ \text { CAN } & \text { Controller Area Network } \\ \text { CNG } & \text { Compressed natural gas }\end{array}$

DC Direct current

EEA European Environmental Agency

EMC Electromagnetic Compatibility

E-motor Electric motor

ERTRAC European Road Transport Research Advisory Council 


\begin{tabular}{llll}
\hline ESM & Electrically Excited Synchronous Machine & MS/s & \multicolumn{2}{c}{ Mega-samples/second } \\
EVE & Electric Vehicles and Environment (IWG of & PEV & $\begin{array}{l}\text { Pure electric vehicle } \\
\text { Plug-in hybrid electric vehicle }\end{array}$ \\
& GRPE) & PHEV & PID controller Proportional-Integral-Derivative \\
GRPE & The Working Party on Pollution and Energy & Pontroller \\
GTR & Global Technical Regulation (of UN ECE) & \multicolumn{2}{c}{ PMSM (PSM) Permanent Magnet Synchronous Motor } \\
HFCEV & Hydrogen fuel cell electric vehicle & SW & Software \\
HD & Heavy duty engine & U(t) & Voltage in the function of time \\
I(t) & Current in the function of time & UN-ECE & United Nations Economic Commission for \\
I/O & Digital inputs/outputs & & Europe \\
ICE & Internal Combustion Engine & VDC & Volts Direct Current \\
IWG & Informal Working Group (of GRPE) & Worldwide harmonized Light vehicles Test \\
LD/LDV & Light-duty engine/light duty vehicle & & Procedure \\
LPG & Liquefied petroleum gas & &
\end{tabular}

\section{Bibliography}

[1] ABE, S. The future direction of the electrified vehicle utilizing of big data. Proceedings "Connectivity - the key to future emission and consumption reduction? In Vehicle and Powertrain" 30th International AVL Conference "Engine \& Environment", 7th-8th June 2018, Graz, Austria.

[2] AVL e-power solutions. General information prospect. 2018.

[3] Automotive News Europe, 2018.

[4] BIELACZYC, P., WOODBURN, J. Current directions in LD powertrain technology in response to stringent exhaust emissions and fuel efficiency requirements. Combustion Engines. 2016, 166(3), 62-75. DOI:10.19206/CE-2016-341.

[5] BIELACZYC, P. Global trends in exhaust emissions and impact on engine technology and fuels: an introduction to the topic. CE-2018-310, Symposium Proceedings of the 6th International Exhaust Emissions Symposium, ISBN No. 978-83-946334-1-7, Bielsko-Biala, Poland 2018.

[6] EEA, 2016. Electric vehicle in Europe. European Environmental Agency (EEA) Report No. 20/2016.

[7] European Commission. White Paper on transport. Publications Office of the European Union, 2011, DOI:10.2832/30955.

[8] Internal BOSMAL Technical Materials. 2016-2018.

[9] IRENA, 2017. Electric Vehicles Technology Brief. International Renewable Energy Agency (IRENA), February 2017.

[10] JURASCHEK, S., BUCHNER, A., SCHINNERL, B. The electric powertrain technology of the BMW Group. 39th International Vienna Motor Symposium 2018. VDI, Reihe 12, Nr. 807, Vol: II, Part 1.

[11] MOCK, P. European vehicle market statistics, 2017/2018. ICCT 28.11.2017.

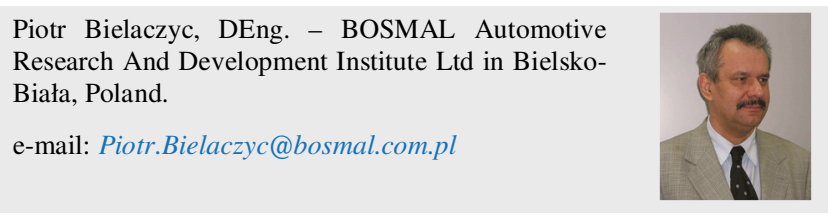

Andrzej Suchecki, DEng. - BOSMAL Automotive Research And Development Institute Ltd in BielskoBiała, Poland.

e-mail: Andrzej.Suchecki@bosmal.com.pl
[12] NEUGEBAUER, S. Technological scenarios for the decarbonization of road transport. Proceedings "Connectivity key to future emission and consumption reduction? In Vehicle and Powertrain" 30th International AVL Conference "Engine \& Environment". 7th-8th June 2018, Graz, Austria.

[13] Proposal for Amendment 4 to Global Technical Regulation No. 15 (Worldwide harmonized Light vehicles Test Procedure (WLTP)), United Nations ECE/Trans/WP.29/GRPE/ 2018/1.

[14] RYŁKO, M., BIELACZYC, P. Electric vehicles: challenges and opportunities, CE-2018-334, Symposium Proceedings of the 6th International Exhaust Emissions Symposium, ISBN No. 978-83-946334-1-7, Bielsko-Biala, Poland 2018.

[15] UN ECE, 2013, Regulation UN ECE No. 85, revision 1, "Uniform provisions concerning the approval of internal combustion engines or electric drivetrains intended for the propulsion of motor vehicles of categories $\mathrm{M}$ and $\mathrm{N}$ with regard to the measurement of net power and the maximum 30 minutes power of electric drivetrains", supplement 6, paragraphs 5.3.1 and 5.3.2. 21 August 2013.

[16] UN ECE, 2018, Electric Vehicles and the Environment (EVE IWG). Report to GRPE 77th Session, Informal Document GRPE-77-28, 7-8 June 2018.

[17] WOLFRAM, P., LUTSEY, N. Electric vehicles: Literature review of technology costs and carbon emissions. ICCT (International Council on Clean Transportation), Working paper 2016-14.

[18] Yokogawa WT 1800, Technical Report English Edition. 2011. 54(2).

Bartosz Hejny, MEng. - BOSMAL Automotive Research And Development Institute Ltd in BielskoBiała, Poland.

e-mail: Bartosz.Hejny@bosmal.com.pl

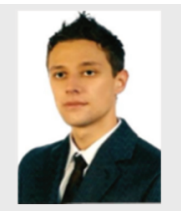

Rafał Sala, DEng. - BOSMAL Automotive Research And Development Institute Ltd in Bielsko-Biała, Poland.

e-mail:Rafal.Sala@bosmal.com.pl
Krzysztof Sobieszczański, MEng. - BOSMAL Automotive Research And Development Institute Ltd in Bielsko-Biała, Poland.

e-mail: Krzysztof.Sobieszczanski@bosmal.com.pl
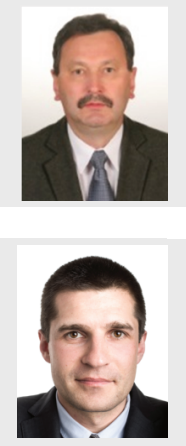
